\title{
Dementia and occupational exposure to organic solvents
}

\author{
Keith Palmer, Hazel Inskip, Christopher Martyn, David Coggon
}

\begin{abstract}
Objectives-To investigate whether occupational exposure to organic solvents increases the risk of dementia

Methods-Cases of dementia were identified from the computed tomography records of eight neuroradiology centres in England and Wales, and were compared with two sets of controls investigated at the same centres. The first set of controls were patients with brain cancer and the second set were patients with other disorders that were not chronically disabling. Lifetime occupational histories were obtained through a postal questionnaire completed by the subjects or their next of kin. Associations between dementia and occupation were examined by logistic regression.

Results-Usable questionnaires were returned for 204 (61\%) of the cases, 225 (51\%) of the controls with brain cancer, and 441 $(61 \%)$ of the other controls. The findings with each of the two sets of controls were similar. In comparison with all controls combined, cases had less often worked ever as a painter or printer (odds ratio (OR) 0.6 , $95 \%$ confidence interval $(95 \% \mathrm{CI}) 0.3$ to 1.2 ), and were less likely to have worked for $>1$ year as a printer, painter, or launderer or dry cleaner (OR $0.6,95 \%$ CI 0.3 to 1.4 ). Conclusions-These findings provide no support for the hypothesis that occupational exposure to solvents is a cause of dementia. An excess risk in subsets of workers with extremes of exposure cannot be discounted, but the data indicate that any influence of exposure to solvents on the overall incidence of severe dementia in the general population of England and Wales is small.

(Occup Environ Med 1998;55:712-715)
\end{abstract}

Keywords: dementia; occupation; solvents

MRC Environmental Epidemiology Unit, University of Southampton, Southampton, UK K Palmer

H Inskip

C Martyn

D Coggon

Correspondence to: Professor David Coggon, MRC Environmental Epidemiology Unit, Southampton General Hospital, Southampton SO16 6YD, UK.

Accepted 8 June 1998 and many cross sectional studies have found broadly consistent deficits in tests of psychomotor function and short term memory among exposed workers. ${ }^{12}$ Furthermore, an association between exposure to solvents and chronic neuropsychiatric illness has been found in epidemiological studies from several countries. ${ }^{3-15}$ The categories of neuropsychiatric disease investigated have varied from study to study, but some have suggested an increased risk of dementia. . $^{3-12-14}$

These findings have led some countries to designate certain categories of neuropsychiatric illness as an occupational disease in workers who have been chronically exposed to solvents. However, uncertainties remain about the range of illness that can be attributed to solvents, and in particular whether solvents contribute to frank dementia. An association with dementia has not been apparent in all investigations. ${ }^{9} 1617$

To try to shed further light on this question, we examined the relation of dementia with exposure to solvents in a community based case-control study.

\section{Method}

Cases of dementia were compared with controls with brain cancer and other neurological disorders. Potential subjects were identified by retrospectively searching the computed tomography (CT) records of eight neuroradiology centres in England and Wales for consecutive periods ranging from 36 to 68 months. In each centre we examined records of all men born in 1916-45 with a possible diagnosis of dementia or primary brain cancer. Also, for each possible case of dementia we selected the next man in the file who was born during the same five-year period and had a diagnosis other than dementia, brain cancer, epilepsy, or chronic disabling disease.

We then reviewed the hospital notes of these patients, excluding from further study those whose notes could not be located (about 20\%), who were private patients, who lived outside the normal catchment area of the neuroradiology centre, whose provisional diagnosis of dementia or brain cancer from the radiology records was not confirmed, or who had first been diagnosed with these diseases before the period being investigated. For the rest, we abstracted the diagnosis, address, name and address of the next of kin, and name and address of the general practitioner.

With permission from the general practitioner, we sent a short postal questionnaire either to the patient himself, or if he had died, to his next of kin. Among other things, this asked whether the patient had ever worked in 
Table 1 Classification of occupations by likely exposure to organic solvents

\begin{tabular}{|c|c|c|c|}
\hline \multicolumn{4}{|c|}{ High exposure: } \\
\hline 087 & Compositors & 101 & Aerographers and paint sprayers \\
\hline 088 & Printing press operators & 102 & Painters and decorators nec \\
\hline 089 & Printers so described & 103 & Coach painters (so described) \\
\hline 090 & Printing workers NEC & 168 & Launderers and dry cleaners \\
\hline \multicolumn{4}{|c|}{ Intermediate or uncertain exposure: } \\
\hline 015 & $\begin{array}{l}\text { Chemical process production } \\
\text { workers NEC }\end{array}$ & 091 & Workers in rubber \\
\hline 038 & Turners & 092 & Workers in plastics \\
\hline 039 & $\begin{array}{l}\text { Machine tool setters and setter } \\
\text { operators NEC }\end{array}$ & 094 & Other production process workers \\
\hline 040 & Machine tool operators & 150 & Garage proprietors \\
\hline 042 & Motor mechanics and auto engineers & 167 & Hairdressers \\
\hline 049 & Press workers and stampers & 209 & Armed forces \\
\hline 057 & Carpenters and joiners & 210 & $\begin{array}{l}\text { Armed forces (commonwealth } \\
\text { and foreign) }\end{array}$ \\
\hline 058 & Cabinet makers & 211 & Inadequately described occupations \\
\hline 063 & Shoe makers and repairers & & \\
\hline \multicolumn{4}{|c|}{ Low exposure: } \\
\hline All o & th & & \\
\hline
\end{tabular}

$\overline{\text { Code numbers refer to the Office of Population Censuses and Surveys } 1966 \text { classification of occu- }}$ pations.

$\mathrm{NEC}=$ not elsewhere classified

each of six specified occupations (printer, painter, driver, shop assistant, gardener, or joiner), and for a record of all jobs held for at least one year since leaving school. Patients who completed their own questionnaires were encouraged to seek help from a member of their family if needed.

Associations between dementia and occupation were examined by logistic regression with allowance for age at CT (treated as a continuous variable), neuroradiology centre, and distance of residence at the time of diagnosis from the neuroradiology centre $(<10 \mathrm{~km}$ or $\geqslant 10$ $\mathrm{km})$. Men were considered to have high occupational exposure to solvents if they had worked for $>1$ year as a printer, painter, or launderer or dry cleaner. Their occupational exposure to solvents was deemed to be low if they did not report having worked in any of these jobs or in others where exposure was classified as intermediate or uncertain (table 1).

\section{Results}

Usable questionnaires were returned for 204 $(61 \%)$ of the dementia cases, 225 (51\%) of the controls with brain cancer, and $441(61 \%)$ of the other controls. Most of the cases had clinical diagnoses of Alzheimer's disease (105) or cerebrovascular dementia (42). The most common diagnoses among the non-brain cancer controls were cerebrovascular disease (195), benign tumours (36), and migraine or headache (30).

Table 2 shows the associations of dementia with work in the six occupations specified in the questionnaire, and also the risk in men with high occupational exposure to solvents compared with low exposure. In separate analyses, the findings with each of the two sets of controls were similar. In comparison with all controls combined, cases were less often reported to have worked as a painter or printer (odds ratio (OR) 0.6, 95\% confidence interval ( $95 \% \mathrm{CI}) \quad 0.3$ to 1.2 ), and were less often classed as having high occupational exposure to solvents (OR 0.6, 95\% CI 0.3 to 1.4 ).

Table 3 shows findings separately for Alzheimer's disease and other types of dementia. Risk estimates for Alzheimer's disease were generally lower than those for other dementias, but even for other dementias, there was no indication of an association with occupational exposure to solvents.

\section{Discussion}

This study provides no support for the hypothesis that occupational exposure to solvents is a cause of dementia. However, interpretation of its negative findings must take into account several potential biases.

There are obvious difficulties in case-control studies of dementia which rely on data obtained from memory. Because we doubted the accuracy of the information that could be elicited, we did not ask directly about occupational exposure to solvents, but restricted our enquiry to job titles. Even so, there is a possibility that the occupational histories obtained for cases were less complete than for controls. This may have contributed to the low risk estimates obtained, particularly for Alzheimer's disease, although it is notable that the ORs for work as a printer or painter, two jobs which often entail substantial exposure to solvents, were lower than for the other occupations specifically asked about.

Table 2 Associations of dementia with occupation and potential occupational exposure to solvents

\begin{tabular}{|c|c|c|c|c|c|c|}
\hline \multirow[b]{2}{*}{ Risk factor } & \multicolumn{3}{|c|}{ Numbers of subjectst } & \multicolumn{3}{|c|}{${ }^{\star}$ Odds ratios (95\% CIs) for comparison with } \\
\hline & $\begin{array}{l}\text { Dementia } \\
\text { cases }\end{array}$ & $\begin{array}{l}\text { Brain cancer } \\
\text { controls }\end{array}$ & $\begin{array}{l}\text { Other } \\
\text { controls }\end{array}$ & $\begin{array}{l}\text { Brain cancer } \\
\text { controls }\end{array}$ & $\begin{array}{l}\text { Other } \\
\text { controls }\end{array}$ & $\begin{array}{l}\text { All } \\
\text { controls }\end{array}$ \\
\hline Never worked as printer & 187 & 190 & 375 & & & \\
\hline Ever worked as printer & 3 & 8 & 14 & $0.3(0.1$ to 1.2$)$ & $0.5(0.1$ to 1.8$)$ & $0.4(0.1$ to 1.5$)$ \\
\hline Never worked as painter & 178 & 178 & 364 & & & \\
\hline Ever worked as painter & 12 & 21 & 29 & $0.8(0.3$ to 1.9$)$ & $0.9(0.4$ to 1.9$)$ & $0.8(0.4$ to 1.6$)$ \\
\hline Never worked as printer or painter & 176 & 173 & 354 & & & \\
\hline Ever worked as printer or painter & 14 & 29 & 43 & $0.5(0.3$ to 1.2$)$ & $0.7(0.4$ to 1.4$)$ & $0.6(0.3$ to 1.2$)$ \\
\hline Never worked as driver & 141 & 143 & 280 & & & \\
\hline Ever worked as driver & 55 & 68 & 123 & $1.0(0.6$ to 1.6$)$ & $1.0(0.7$ to 1.5$)$ & $1.0(0.7$ to 1.4$)$ \\
\hline Never worked as shop assistant & 173 & 176 & 341 & & & \\
\hline Ever worked as shop assistant & 17 & 20 & 52 & $0.9(0.4$ to 1.9$)$ & $0.6(0.3$ to 1.1$)$ & $0.7(0.4$ to 1.2$)$ \\
\hline Never worked as gardener & 177 & 180 & 357 & & & \\
\hline Ever worked as gardener & 12 & 19 & 33 & $0.6(0.3$ to 1.4$)$ & $0.8(0.4$ to 1.6$)$ & $0.7(0.4$ to 1.4$)$ \\
\hline Never worked as joiner & 176 & 177 & 366 & & & \\
\hline Ever worked as joiner & 15 & 16 & 24 & $1.2(0.5$ to 2.9$)$ & $1.4(0.7$ to 2.7$)$ & $1.3(0.7$ to 2.5$)$ \\
\hline Low occupational exposure to solvents & 151 & 164 & 305 & & & \\
\hline High occupational exposure to solvents & 8 & 17 & 28 & $0.7(0.3$ to 1.8$)$ & $0.7(0.3$ to 1.5$)$ & $0.6(0.3$ to 1.4$)$ \\
\hline
\end{tabular}

*All odds ratios are adjusted for age, neuroradiology centre, and distance of residence from neuroradiology centre. Each risk factor was analysed in a separate logistic regression model.

†Data on specific occupations were missing for some subjects. 
Table 3 Associations of Alzheimer's disease and other dementia with occupation and potential occupational exposure to solvents

\begin{tabular}{|c|c|c|c|c|c|}
\hline \multirow[b]{2}{*}{ Risk factor } & \multirow[b]{2}{*}{ Controlst (n) } & \multicolumn{2}{|c|}{ Alzheimer's disease } & \multicolumn{2}{|c|}{ Other dementia } \\
\hline & & Casest (n) & ${ }^{\star} O R(95 \% C I)$ & Casest (n) & ${ }^{\star} \mathrm{OR}(95 \% \mathrm{CI})$ \\
\hline Never worked as printer & 565 & 98 & & 89 & \\
\hline Ever worked as printer & 22 & 1 & $0.2(0.0$ to 1.8$)$ & 2 & $0.7(0.1$ to 2.9$)$ \\
\hline Never worked as painter & 542 & 96 & & 82 & \\
\hline Ever worked as painter & 50 & 4 & $0.5(0.2$ to 1.4$)$ & 8 & $1.4(0.6$ to 3.0$)$ \\
\hline Never worked as printer or painter & 527 & 95 & & 81 & \\
\hline Ever worked as printer or painter & 72 & 5 & $0.4(0.1$ to 1.0$)$ & 9 & $1.0(0.5$ to 2.2$)$ \\
\hline Never worked as driver & 423 & 78 & & 63 & \\
\hline Ever worked as driver & 191 & 24 & $0.8(0.5$ to 1.3$)$ & 31 & $1.2(0.8$ to 2.0$)$ \\
\hline Never worked as shop assistant & 517 & 91 & & 82 & \\
\hline Ever worked as shop assistant & 72 & 9 & $0.7(0.3$ to 1.5$)$ & 8 & $0.7(0.3$ to 1.5$)$ \\
\hline Never worked as gardener & 537 & 94 & & 83 & \\
\hline Ever worked as gardener & 52 & 5 & $0.6(0.2$ to 1.5$)$ & 7 & $0.9(0.4$ to 2.0$)$ \\
\hline Never worked as joiner & 543 & 92 & & 84 & \\
\hline Ever worked as joiner & 40 & 8 & $1.2(0.5$ to 2.8$)$ & 7 & $1.4(0.6$ to 3.3$)$ \\
\hline Low occupational exposure to solvents & 469 & 75 & & 76 & \\
\hline High occupational exposure to solvents & 45 & 2 & $0.3(0.1$ to 1.3$)$ & 6 & $1.0(0.4$ to 2.5$)$ \\
\hline
\end{tabular}

^All odds ratios are adjusted for age, neuroradiology centre and distance of residence from neuroradiology centre. Each risk factor was analysed in a separate logistic regression model. Comparisons are with all controls combined.

†Data on specific occupations were missing for some subjects.

Job titles were used as surrogates for exposure in our analysis. Variation in exposure level may have existed, even within exposed occupations - such as printers. A more specific test of association in subsets with exceptional exposure (for example, rotagravure printers rather than printers as a whole) was not possible, and we therefore cannot discount an excess risk at extremes of exposure. However, the number of cases with such high levels of occupational exposure would be small.

To reduce recall bias we encouraged subjects to seek help from a relative when completing the questionnaire, and we used patients with brain cancer as one of our control groups. By the time of the study, many of the controls with brain cancer had died, and of necessity the information about them had to be obtained from their next of kin. The greater difficulty in contacting families once patients had died was the main reason for the lower response rate for brain cancer controls. We have no reason, however, to suspect that the incomplete participation of any of the patient groups would have led us to underestimate importantly the risks associated with solvents.

A disadvantage of choosing brain cancer as a control diagnosis was the possibility that solvents cause this disease as well as dementia. However, the evidence for such an effect is weak. Moreover, risk estimates obtained with the other control group were similar to those found with the brain cancer controls.

Another potential source of bias lay in the patterns of referral to neuroradiology centres. Our patients with dementia tended to live closer to the centres than the controls, and the prevalence of particular occupations varies geographically. For this reason, we controlled in our analysis for distance of residence from the neuroradiology centre. We do not think that referral is likely to have been influenced directly by the subjects' exposure to solvents. In Britain there has been much less publicity and concern about the possible links between solvents and chronic neuropsychiatric disease than in some other countries. Furthermore, if there were a lower threshold for investigating patients with known exposure to solvents, the effect would be to inflate risk estimates, and the bias would not account for our negative results.

Most of the previous epidemiological studies that have suggested an association between dementia and exposure to solvents have focused on people awarded disability pensions for the disorder. ${ }^{3-6} 9^{10}$ In a case-control study that used records of a Swedish pension fund, Axelson et al found that seven (29\%) of 24 subjects receiving pensions for dementia had worked in painting, varnishing, or carpet laying compared with 35 (14\%) of 248 referents. ${ }^{3}$ Similarly, a Danish study of people with disability pensions from a union of carpenters and cabinet makers found a doubling of the risk of dementia in those with prolonged indoor exposure to organic solvents ${ }^{4}$; and in a Danish cohort study, painters had a relative risk of about 3.5 for being awarded a disability pension because of cryptogenic presenile dementia. ${ }^{5}$ Against this, a case-control study of men receiving disability compensation in the United States found a lower risk of presenile dementia in painters than in bricklayers (OR 0.44 ), but the associated $95 \%$ CI was wide. ${ }^{9}$

A positive association between exposure to solvents and dementia was also found in a case-control study among members of a health maintenance organisation in Seattle. ${ }^{14}$ In this investigation the cases were newly diagnosed with probable Alzheimer's disease, and were identified from various sources including primary care clinics.

Studies which have identified cases only from hospital records have produced less consistent results. A Danish study of geriatric patients with dementia found a crude relative risk of 2.0 for always versus never exposed to solvents in the longest held job, as estimated by a job exposure matrix ${ }^{12}$; and in a case-control study of men admitted to hospitals in Quebec, work in moderate or high solvent concentrations for $\geqslant 10$ years was associated with ORs of 1.2-1.5 for senile or presenile dementia and 3.7-4.0 for alcoholic dementia. ${ }^{13}$ On the other hand, case-control studies of Alzheimer's disease in Massachusetts, ${ }^{17}$ Minneapolis, ${ }^{18}$ and Sydney ${ }^{19}$ found little or no evidence of any 
association with exposure to solvents, with ORs all $<1.4$, not significant.

Nor did any clear increase of risk emerge in a British case-control investigation of presenile dementia that identified cases and their occupations from death certificates. ${ }^{16}$

Several factors may have contributed to the apparent discrepancies in these findings. In some studies based on disability pensions there may have been a diagnostic bias, with a tendency for pensions to be awarded more readily for minor degrees of dementia if the claimant was known to have been exposed to a suspected occupational cause of the disorder. Also, results may have been influenced by the mix of cases studied. For example, disease may have been less severe in the Seattle study, ${ }^{14}$ where $40 \%$ of cases were identified from primary care clinics, than in investigations based only on patients diagnosed in hospital. Also, the categories of dementia examined have varied from study to study. Some have focused specifically on Alzheimer's disease whereas others have included a wider range of diseases. The investigation in Quebec ${ }^{13}$ suggested that the risks associated with exposure to solvents may be higher for alcoholic dementia than for other types. Finally, many of the studies have been based on few cases, and part of the variation in results may be attributable to chance.

Whatever the explanation for the inconsistency, our findings argue against a large influence of occupational exposure to solvents on the overall burden of severe dementia in the general population of England and Wales.

We thank Graham Wield for his assistance with the computing and Brian Pannett for his advice on patterns of exposure to solvents by occupation.

1 Baker ELJ, Smith TJ, Landrigan PJ. The neurotoxicity of industrial solvents: a review of the literature. $\mathrm{Am}$ f Ind Med industrial solven

2 Baker EL. A review of recent research on health effects of human occupational exposure to organic solvents: a critical review. F Occup Med 1994;36:1079-92.
3 Axelson O, Hane M, Hogstedt C. A case-referent study on neuropsychiatric disorders among workers exposed to solvents. Scand f Work Environ Health 1976;2:14-20.

4 Olsen J, Sabroe S. A case-reference study of neuropsychiatric disorders among workers exposed to solvents in the Danish wood and furniture industry. Scand $\mathcal{F}$ Soc Med 1980;8:44-9.

5 Mikkelsen S. A cohort study of disability pension and death among painters with special regard to disabling presenile dementia as an occupational disease. Scand 7 Social Med 1980;8:34-43.

6 Lindstrom K, Riihimaki H, Hanninen K. Occupational solvent exposure and neuropsychiatric disorders. Scand $\mathcal{F}$ Work Environ Health 1984;10:321-3.

7 van Vliet C, Swaen GMH, Volovics A, et al. Exposureoutcome relations between organic solvent exposure and neuropsychiatric disorders: results from a Dutch casecontrol study. Am f Ind Med 1989;16:707-18.

8 Guberan E, Usel M, Raymond L, et al. Disability, mortality, and incidence of cancer among Geneva painters and electricians: a historical prospective study. $\mathrm{Br} f \mathrm{Ind} \mathrm{Med}$ 1989;46:16-23.

9 Brackbill RM, Maizlish N, Fischbach T. Risk of neuropsychiatric disability among painters in the United States. Scand $\mathcal{F}$ Work Environ Health 1990;16:182-8.

10 Riise T, Moen B. A nested case-control study of disability pension among seamen, with special reference to neuropsychiatric disorders and exposure to solvents. Neuroepidemiology 1990;9:88-94.

11 Lundberg I, Gustavsson A, Hogberg M, et al. Diagnoses of alcohol abuse and other neuropsychiatric disorders among house painters compared with house carpenters. $\mathrm{Br} \mathcal{F}$ Ind Med 1992;49:409-15.

12 Rasmussen H, Olsen J, Lauritsen J. Risk of encephalopathia among retired solvent-exposed workers. A case-control study among males applying for nursing home accommodation or other types of social support facilities. F Occup Med 1985;27:561-6.

13 Cherry NM, Labreche FP, McDonald JC. Organic brain damage and occupational solvent exposure. $\mathrm{Br} \mathcal{F}$ Ind $\mathrm{Med}$ 1992;49:776-81.

14 Kukull WA, Larson EB, Bowen JD, et al. Solvent exposure as a risk factor for Alzheimer's disease: a case-control study. Am f Epidemiol 1995;141:1059-79.

15 Nelson NA, Robins TG, White RF, et al. A case-control study of chronic neuropsychiatric disease and organic solvent exposure in automobile assembly plant workers. Occup Environ Med 1994;51:302-7.

16 O'Flynn RR, Monkman SM, Waldron HA. Organic solvents and presenile dementia: a case referent study using death certificates. Br f Ind Med 1987;44:259-62.

17 Shalat SL, Seltzer B, Pidcock C, et al. Risk factors for Alzheimer's disease: a case-control study. Neurology 1987; 37:1630-3.

18 French LR, Schuman LM, Mortimer JA, et al. A case-control study of dementia of the Alzheimer type. Am $\mathcal{F}$ Epidemiol 1985;121:414-21.

19 Gun RT, Korten AK, Jorm AF, et al. Occupational risk factors for Alzheimer disease: a case-control study. Alzheimer Dis Assoc Disord 1997;11:21-7. 